\title{
Management of the Aging Face
}

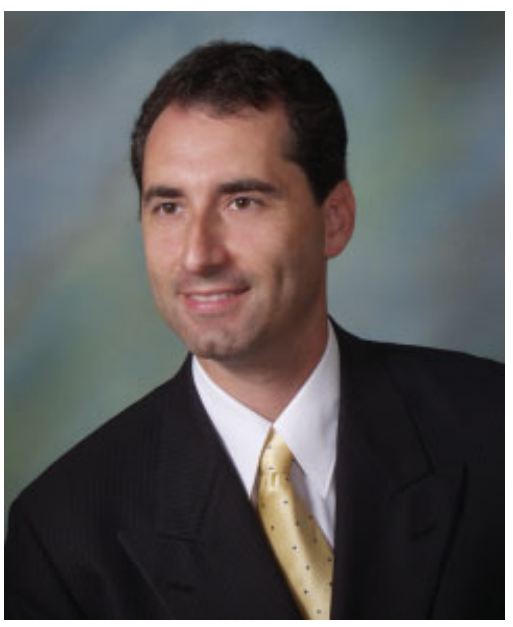

$\mathrm{I}_{\mathrm{t}}$ is my pleasure to present this issue of Facial Plastic Surgery. As a subscriber to either Facial Plastic Surgery or Seminars in Plastic Surgery, you are receiving an issue of both journals, which have been coordinated to discuss matters related to facial rejuvenation. This issue of Facial Plastic Surgery focuses on comprehensive facial rejuvenation, and the complementary issue of Seminars in Plastic Surgery focuses specifically on face and neck lifting. We have brought together an eclectic mix of renowned authors from diverse backgrounds and specialties. These experts have graciously shared their unique perspectives and tips so we all may provide the best results possible for our patients. It is our hope that this may serve as a model for future interdisciplinary endeavors, and we wish to thank all authors for their efforts.

Coordinating one journal issue is difficult enough, but these issues would not have been possible without the assistance of Daniel Hatef, M.D., and Lydia Bebczuk, as well as the entire Thieme staff. I also want to acknowledge the vision that the editors at Thieme have demonstrated in supporting this joint effort. I hope you, the reader, enjoy and benefit from these issues as much as I have.

Anthony P. Sclafani, M.D., F.A.C.S. ${ }^{1}$

Guest Editor
${ }^{1}$ Director of Facial Plastic Surgery, The New York Eye and Ear Infirmary, New York, New York; and Professor of Otolaryngology, New York Medical College, Valhalla, New York.

Address for correspondence and reprint requests: Anthony P. Sclafani, M.D., F.A.C.S, Director of Facial Plastic Surgery, The New York Eye and Ear Infirmary, 310 East 14th Street, Sixth Floor, North Building, New York, NY 10003 (e-mail: asclafani@nyee.edu).
Management of the Aging Face; Guest Editor, Anthony P. Sclafani, M.D., F.A.C.S.

Facial Plast Surg 2009;25:213-214. Copyright (C) 2009 by Thieme Medical Publishers, Inc., 333 Seventh Avenue, New York, NY 10001, USA. Tel: +1(212) 584-4662.

DOI 10.1055/s-0029-1242031. ISSN 0736-6825. 